Vol. 6, No. 3-4, 2020

\author{
Anatoliy Kuzey ${ }^{1}$, Vladimir Lebedev ${ }^{2}$, Andrii Slipchuk ${ }^{3}$, Pavel Tsykunov ${ }^{4}$, Igor Yurchyshyn ${ }^{5}$ \\ ${ }^{1}$ State scientific institution "Physical-Technical Institute of the national academy of sciences of Belarus", \\ Kuprevich Str. 10, Minsk, Republic of Belarus, e-mail: anatkuzei@phti.by, ORCID 0000-0002-6715-7964 \\ ${ }^{2}$ State scientific institution "Physical-Technical Institute of the national academy of sciences of Belarus", \\ Kuprevich Str. 10, Minsk, Republic of Belarus, e-mail: fti_lebedev@mail.ru, ORCID 0000-0003-2891-9708 \\ ${ }^{3}$ Department of Robotics and Integrated Mechanical Engineering Technologies, Lviv Polytechnic National \\ University, S. Bandery Str. 12, Lviv, Ukraine, E-mail: andrii.m.slipchuk@lpnu.ua, ORCID 0000-0003-0584-6104 \\ ${ }^{4}$ State scientific institution "Physical-Technical Institute of the national academy of sciences of Belarus", \\ Kuprevich Str. 10, Minsk, Republic of Belarus, e-mail: zamaranthz@mail.ru \\ ${ }^{5}$ Department of Robotics and Integrated Mechanical Engineering Technologies, Lviv Polytechnic National \\ University, S. Bandery Str. 12, Lviv, Ukraine, E-mail: yur@center-sapr.com
}

\title{
MECHANISMS OF STRUCTURAL-PHASE TRANSFORMATIONS DURING CRYSTALLIZATION OF A SOLDER MELT
}

Received: November 10, 2020 / Revised: December 24, 2020 / Accepted: December 30, 2020

(C) Kuzey A., Lebedev V., Slipchuk A., Tsykunov P., Yurchyshyn I., 2020

Abstract. Problem statement. An important requirement is quality assurance of joining materials with minimal overheating of materials, lowering the soldering temperature and suppressing the interaction of the solder with the materials to be soldered. The heating of the solder and the holder should be as uniform as possible and with a minimum temperature difference along the depth. One solution may be to develop more efficient solders and fluxes, adapted to the high heating rates that are typical when using high frequency currents Purpose. Thus, the problems of uniform heating of parts during brazing are relevant. This is necessary for optimal distribution of the electromagnetic field in the contact area Methodology. The effect of the heating rate was investigated. The composition of the flux and solders on the microstructure of the solders and the brazed seam was performed on the joints of HV510 (DIN), HS345 (DIN), HG30 (DIN) hardmetal plates with steel holders made of 5135 (USA) steel with a section of $25 \times 20$. Results. The research of the processes showed that during the contact interaction of low-melting and refractory components of the solders, when the tool was soldered, the solder is formed in the seam and proceeds through several stages. Practical value. Contact interaction of copper-zinc melts with iron particles does not lead to complete dissolution of iron particles. This is explained to the low values of the solubility of iron in copper-zinc melts despite the fact that resistive heat release occurs in the particles. Such iron particles (iron-based alloy) act as a dispersed phase in the structure of the composite material.

Keywords: microstructure, sintered mixture, solder burden, inhomogeneous, carbide tools, heterogeneity area, brazed seams, intermetallic, solder melt.

\section{Introduction}

If you use more advanced equipment, new tooling materials, it would provide an improvement in the efficiency of metalworking tools. They can be made of hard alloys, superhard materials based on cubic boron nitride $(\mathrm{CBN})$ and diamond [1]-[3].

The brazed tool is quite popular, despite the overwhelming use in modern metalworking of blade tools with replaceable multifaceted inserts made of hard alloys and superhard materials. This is especially important for single and small batch production, repair work and unique operations.

Re-sharpening of blades for specific production conditions and technological combinations "processed material - tool material - requirements of the drawing part" allows us to most effectively control the processing modes and achieve a given level of parameters of the processed surface [4], [5]. 


\section{Anatoliy Kuzey, Vladimir Lebedev, Andrii Slipchuk, Pavel Tsykunov, Igor Yurchyshyn}

\section{Problem statement}

Toughening cutting conditions and application of new tool materials requires an appropriate improvement the strength and reliability of their joint with the body. An important requirement is quality assurance of joining materials with minimal overheating of materials, lowering the soldering temperature and suppressing the interaction of the solder with the materials to be soldered. The heating of the solder and the holder should be as uniform as possible and with a minimum temperature difference along the depth. It is quite problematic to fulfill these requirements when soldering parts in induction heating installations using non-magnetic solders because the heating of the solder occurs due to heat transfer from the heated holder.

Heat sources count with induced by high-frequency currents in the solder is small. It is possible to significantly increase the heating rate of the solder in the joint if you use fluxes with a melting point lowered to $650 \ldots 750 \mathrm{~K}$. This is due to the convection of the flux melt under the influence of magnetodynamic forces that are created by the electromagnetic field of the induction device. Thus, the problems of uniform heating of parts during brazing are relevant. One solution may be to develop more efficient solders and fluxes, adapted to the high heating rates that are typical when using high frequency currents. Also relevant in this technology is the relative position of the inductor and the part. This is necessary for optimal distribution of the electromagnetic field in the contact area.

\section{Review of modern information sources on the subject of the paper}

Nowadays induction brazing is the most common method for making carbide tools. When it is soldered, ready-made solders and fluxes, and specialized induction equipment are used [6]-[8]. The efficiency of induction heating is determined by many factors: characteristics of the generator and inductor (current frequency, proximity effect, etc.), physicochemical characteristics of the materials to be joined [9]-[11]. When the generator current frequency increases, then the difference in temperatures on the surface and in the depth of the soldered materials sharply rises. Temperature gradients in the near-surface layers of brazed materials, differences in thermal conductivity of hard alloys and structural steels, and at the same time high brazing temperatures, lead to the formation of cracks in the tool, brazed seams, and oxidation of hard alloys [12], [13]. It is possible to neutralize the influence of temperature gradients, differences in the physicochemical characteristics of the materials to be joined if the soldering temperatures are reduced.

Brazing alloys based on $\mathrm{Cu}-\mathrm{Zn}-\mathrm{Ni}-\mathrm{Mn}$ systems with brazing temperatures of $1225 \ldots 1275 \mathrm{~K}$ are widely used for brazing hard alloy plates to steel holders [10], [11]. Reduced soldering temperature and a change in the microstructure of the soldered seams makes it possible to increase their strength and reduce the effect of high temperatures on hard alloys.

\section{Research methods and equipment}

The effect of the heating rate was investigated. The composition of the flux and solders on the microstructure of the solders and the brazed seam was performed on the joints of HV510 (DIN), HS345 (DIN), HG30 (DIN) hardmetal plates with steel holders made of 5135 (USA) steel with a section of $25 \times 20$. The gap between the working part of the holder and the inductor was chosen in the range of $10 \ldots 40 \mathrm{~mm}$. A single-turn inductor with a conductor cross-section of $12 \times 12 \mathrm{~mm}$ was used for the experiment. The size of the gap between the inductor and the brazed part of the holder allows to change the drop of temperature in the part of the holder - carbide plate. The steel-steel connection was performed on cylindrical specimens with a diameter of $10 \mathrm{~mm}$ made of Steel 45 by soldering their ends using an annular inductor.

The choice of the generator frequency is determined by the size and shape of the product. The heating of the soldering zone was controlled by moving the part relative to the inductor. A high-frequency generator with a power of $80 \mathrm{~kW}$ was used as a source heating. The soldering working frequency was $49.5 \mathrm{kHz}$. Rates heating were $40 \ldots 50 \mathrm{~K} / \mathrm{s}$.

The study of the morphology and microstructure of the surfaces of the holders, hardmetal plates, brazed joints and processed plates of hard alloys was carried out on scanning electron microscopes VEGA TESCAN and MIRAS TESCAN, the MICRO hardware complex, optical microscopes MBS2000 and 


\section{Mechanisms of Structural-Phase Transformations During Crystallization of a Solder Melt}

BMI1. Durometric measurements were performed on a Duramin 5 micro hardness-testing machine. The temperature of the carbide cutter insert and the tool body was controlled by an Optris-CT2MH pyrometer with a measured temperature range of $660 \ldots 1775 \mathrm{~K}$. The microstructure of the solders in the brazed joints was revealed by etching in a 30\% solution of nitric (1 mass fraction) and hydrochloric acid (3 mass fractions). As solders, we used a mixture of powders of copper-zinc alloys (L63, PS63), copper-phosphorous alloy powder ( $8 \%$ mass fraction) with additives of nickel and iron powders (concentration $10 \%$ mass fraction). As a flux, we used a composite material in the form of glass particles $\mathrm{KBF} 4-\mathrm{Na}_{2} \mathrm{~B}_{4} \mathrm{O}_{7}$ of a eutectic alloy, in which there are particles of the $\mathrm{KCl}-\mathrm{NaCl}$ eutectic in an amount of $10 \%$ mass fraction.

\section{Main part}

The formation of a solder melt in the process of induction heating of a charge from a composite solder (Cu-P) $10 \%$ mass $\mathrm{Fe}$ and a flux begins with the formation of a liquid phase - a flux melt. The interaction between the components of the solder takes place in the liquid flux. The process takes place after the melt of the low-melting component has been formed. The solder is a three-phase system as the solder heats up in the temperature range $1075 \ldots 1100 \mathrm{~K}$. It consists of a flux melt and suspension interlayer from a melt of a low-melting component and particles of a high-melting component (Fig. 1).

Stratification of the flux melt and liquid metal suspension of the low-melting component takes place in the temperature range of $1075 \ldots 1100 \mathrm{~K}$ - the refractory component of the solder. However, flux droplets are present in the structure of the liquid-metal suspension (Fig. $1 a, b$ ). A subsequent increase in the temperature of the solder until the soldering temperature is reached is accompanied by the dissolution of the refractory component in the low-melting point and the interaction of the melt with the holder material.

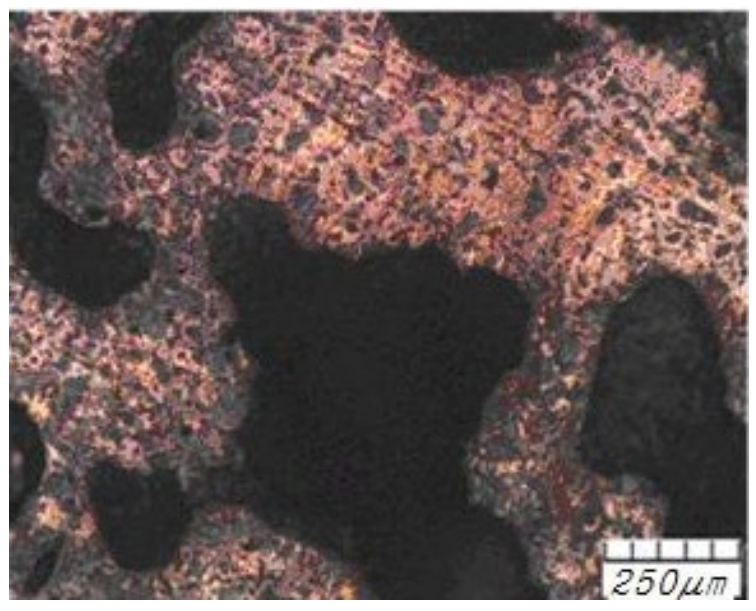

$a$

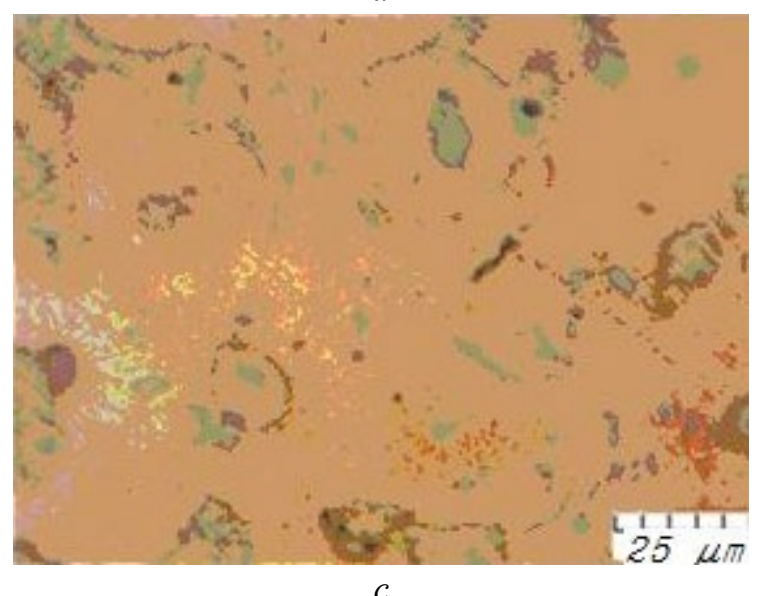

$c$

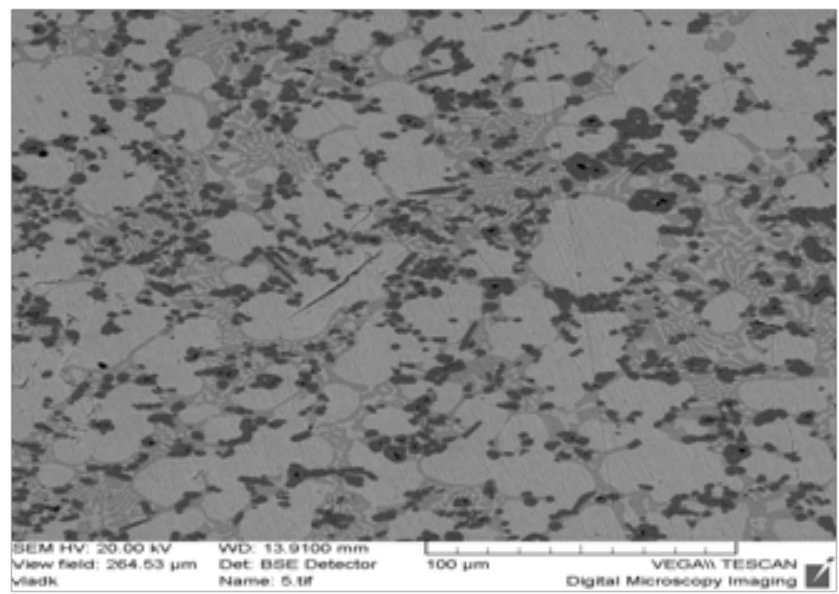

b

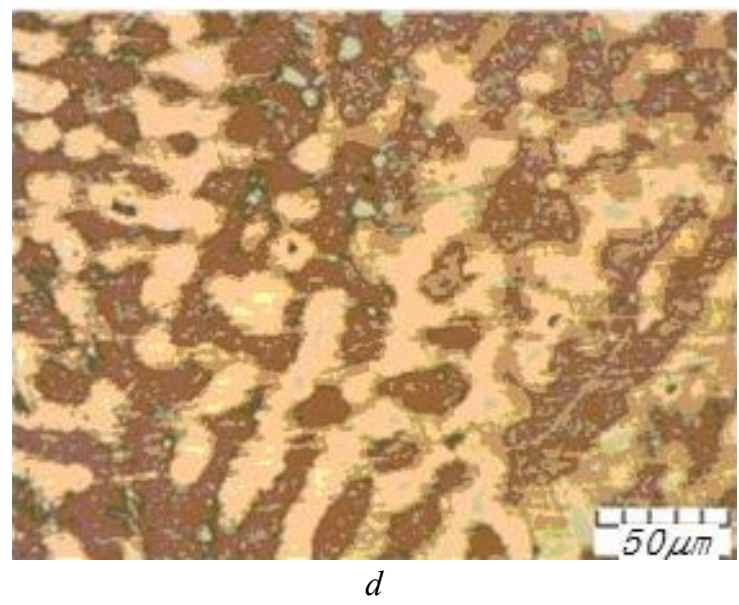

Fig. 1. Microstructure of Cu-P-10\% mass Fe solder after heating the charge (heating rate $40 \mathrm{~K} / \mathrm{s}$ ): $a$ - up to $1000 \mathrm{~K} ; b$ - up to $1075 \mathrm{~K} ; c$ - time for keeping $3 \mathrm{~s}$ at $1125 \mathrm{~K}$; $d$ - time for keeping $6 \mathrm{~s}$ at $1125 \mathrm{~K}$ 


\section{Anatoliy Kuzey, Vladimir Lebedev, Andrii Slipchuk, Pavel Tsykunov, Igor Yurchyshyn}

If you continue to increase the temperature of the solder until the soldering temperature is reached, then the process is accompanied by the dissolution of the refractory component in the low-melting component and the interaction of the melt with the holder material. Depending on the composition of the low-melting and refractory components, the rate heating of the solder, the frequency of the electromagnetic field, the duration heating and the soldering temperature, solders with different microstructure are formed.

If the composite solder $\mathrm{CuP}-10 \%$ mass $\mathrm{Fe}$ is heated to $1125 \mathrm{~K}$ soldering temperature, then it is accompanied by the dissolution of iron particles in the melt and a change in the microstructure formed in this alloy. The formation of a homogeneous microstructure for the alloy (solder) Cu-Fe-P ends only after retention interval the melt at $1125 \mathrm{~K}$ during 6 seconds. Iron particles are present in the structure of the alloy (Figure $1 b, c$ ) if retention interval is less for the solder melt. The microstructure of solders is a matrix of copper alloy. During $1 \ldots 3 \mathrm{~s}$ we did retention interval and temperatures of $1000 \ldots 1125 \mathrm{~K}$.

Shapeless clumps of copper-iron-phosphorus alloy are located in it and they are enriched with phosphorus and iron. In the matrix of copper alloy (doped with phosphorus and iron) are particles of ironphosphorus alloy. The same particles are located in the clumps of the iron-phosphorus-copper alloy (Fig. 1, b, c). The use of solders as a low-melting component in the alloy of the Cu-Zn system ( $\mathrm{Cu}-36 \ldots 38 \%$ mass $\mathrm{Zn}$ ) with higher melting temperatures than in the alloys of the $\mathrm{Cu}-\mathrm{P}$ system changes the microstructure of the solders. Iron particles in the copper-zinc melt dissolve if the solder burden is heated to a temperature of $1175 \mathrm{~K}$.

If the duration of retention interval for the melt is increased, it is accompanied by an increase in the size of diffusion grains on the surface of iron particles, dissolution of iron particles in a copper-zinc melt, and an increase in the size of a copper-zinc-iron alloy (Fig. 2 b). Non-dissolved iron particles are fixed after 3 seconds of exposure in the alloy structure (Fig. 2 c).

Burden heating Cu-38\% mass $\mathrm{Zn}-10 \mathrm{wt} . \% \mathrm{Fe}$ up to $1200 \mathrm{~K}$ led to partial dissolution of iron particles in copper-zinc melt (Fig. $2 b$ ). In the structure of the solder there are small $(5 \ldots 10 \mu \mathrm{m})$ iron particles, there are also larger $(40 \ldots 50 \mu \mathrm{m}$ ) and flux interlayers (Fig. $2 \mathrm{~b}$ ). A magnification time of retention interval the melt (suspension) during 3 seconds at $1200 \mathrm{~K}$ led to a decrease in the amount of large $(40 \ldots 50 \mu \mathrm{m})$ iron particles in the alloy structure. Large iron particles are round and elongated and they are present in the structure of the solder. Particles are clumps of smaller particles. This shows that the temperature of the particles is higher than the holding (soldering) temperature. Large particles are in the form of clumps and they are formed by the coalescence of smaller particles. A subsequent increase in the retention interval does not led to the formation of a homogeneous alloy structure. There are areas in the structure of individual grains. The composition of which is different from the neighboring areas (and grains). The sizes of such areas are $5 \ldots 10 \mu \mathrm{m}$, the size of dendrites is $10 \ldots 30 \mu \mathrm{m}$ (Fig. $2 d$ ).

If we use nickel powder as a refractory component of the solder, this led to the formation of the microstructure of the brazed joint (Fig. 3). The microstructure of the solder is represented by grains with an inhomogeneous structure, which was obtained by a retention interval during 3 seconds. The composition is separated by layers of eutectic (Fig. $3 a$ ). Increasing the retention interval time up to 6 seconds homogenizes the microstructure of the solder. However, the structure of the solder contains particles of a different composition (Fig. 3 b).

The structure of the solders differs from the structure of alloys for a similar composition. It does not depend on the retention interval time of solders melts for $\mathrm{Cu}-\mathrm{P}-\mathrm{Fe}$ or $\mathrm{Cu}-\mathrm{Zn}-\mathrm{Fe}$ (Ni) systems. For metallurgical composition: there are no dendrite forms characteristics of cast alloys; colonies of dendrites have a different structure; individual types of structure cannot be attributed to the structures formed during crystallization of melts in equilibrium conditions (Figs. 2, 3).

Alloys (solders) with similar structures can be formed as a result of contact interaction of lowmelting and high-melting components when exposed to a high-frequency electromagnetic field. The formations of homogeneous melts composition are in different states of aggregation during the contact interaction of two or more components. They have different physical and chemical characteristics. The process takes place through a series of stages, which are also influenced by high-frequency electromagnetic 


\section{Mechanisms of Structural-Phase Transformations During Crystallization of a Solder Melt}

effects [15]. Contact interaction in the solid metal - melt system is described within the framework of the basic concepts of diffusion kinetics under equilibrium conditions [15], [16]. The process of dissolution for a solid metal into a liquid is controlled by the diffusion of atoms in the dissolving metal through the diffusion boundary layer. The dimensions depend from hydrodynamic conditions at the solid-melt interface [17], [18]. At the interface between solid metal and melt, we have two competing processes: diffusion of metal atoms in a solid state in a melt; diffusion of metal atoms in a liquid state into a solid metal [17], [18].

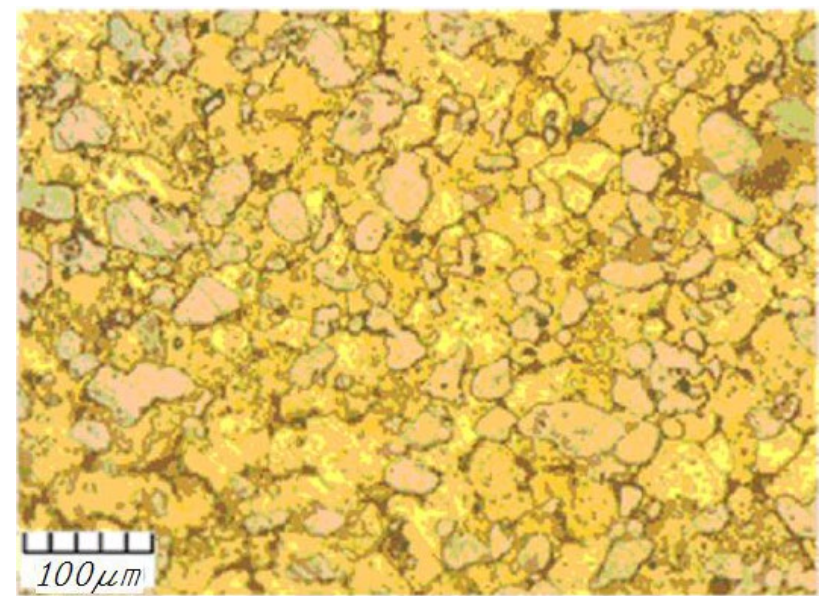

$a$

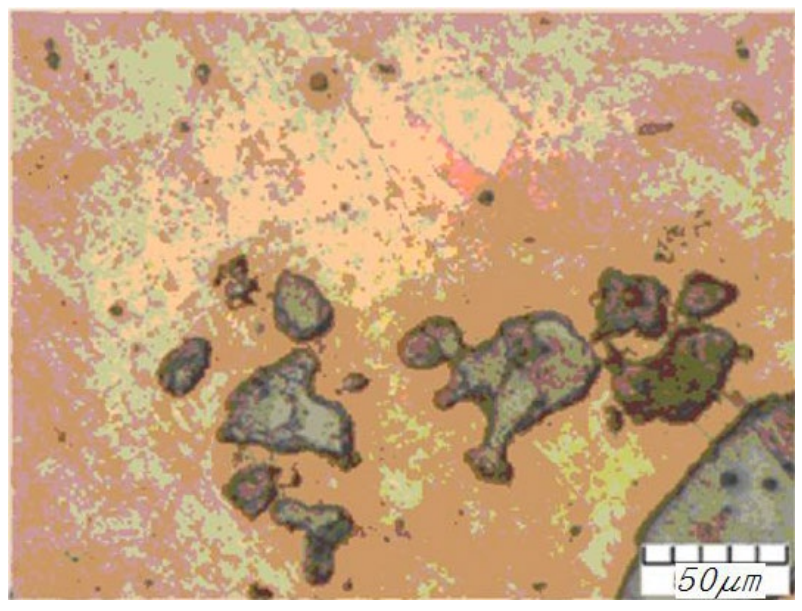

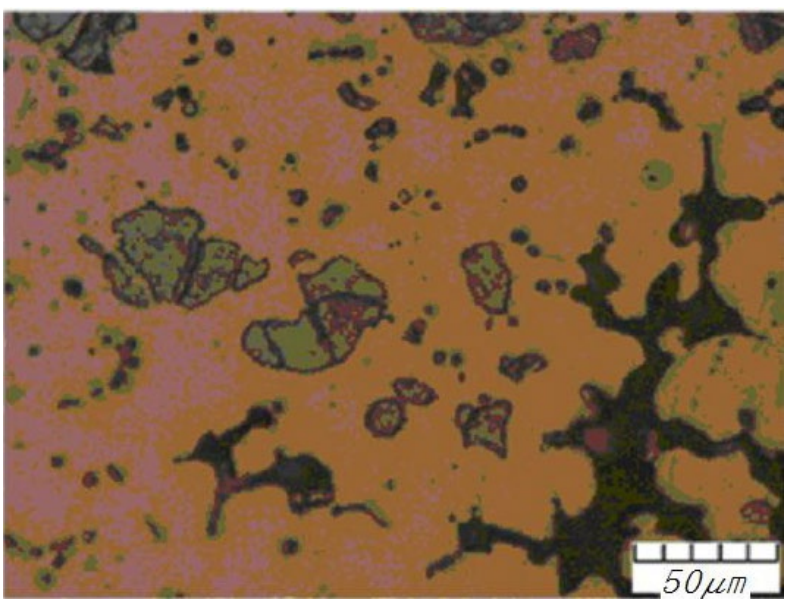

$b$

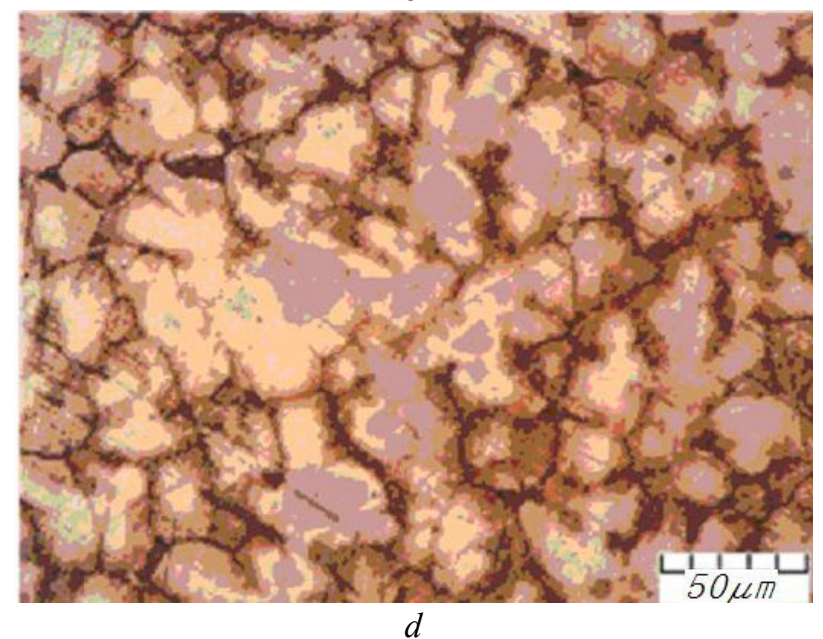

Fig. 2. Microstructure of solder $\mathrm{Cu}-34 \%$ mass $\mathrm{Zn}-10 \%$ mass $\mathrm{Fe}$ :

$a$-heating temperature is $1200 \mathrm{~K}$ during $1 \mathrm{~s}$. Heating rate $40 \mathrm{~K} / \mathrm{s} ; b$-heating temperature is $1200 \mathrm{~K}$ during $3 \mathrm{~s}$. Heating rate $40 \mathrm{~K} / \mathrm{s} ; c$ - heating temperature is $1200 \mathrm{~K}$ during $6 \mathrm{~s}$. Heating rate $40 \mathrm{~K} / \mathrm{s}$; $d$ - heating temperature is $1200 \mathrm{~K}$ during $6 \mathrm{~s}$. Heating rate $35 \mathrm{~K} / \mathrm{s}$

Depending on metal-chemical characteristics of the components for solid metal - melt system, the diffusion of atoms from liquid metal to solid leads to the formation of intermetallic interlayers at the interface. The dimensions are determined by the hydrodynamic conditions at the interface. In accordance with these provisions, contact interaction in the systems $\mathrm{Cu}-\mathrm{P}-\mathrm{Fe},(\mathrm{Cu}-\mathrm{Zn})-\mathrm{Fe},(\mathrm{Cu}-\mathrm{Zn})-\mathrm{Ni}$ should ultimately lead to the formation of multicomponent melts. The product alloys should have a structure of grains (dendrites) of a complex alloyed solid solution based on copper, interlayers of eutectic and intermetallic particles upon cooling. The structure of the alloys will contain particles of nickel, iron with diffusion zones on the surface (Fig. 2) at the initial stages of contact interaction. In addition, there are undissolved particles of nickel, iron, and also shapeless particles with a higher content of nickel (iron) than the surrounding alloy (Figs. 1-3) in the structure of alloys. The formation of such microstructures cannot be explained on the basis of only the diffusion kinetic concepts for solid metal dissolution in liquid ones, as well as the theory of metal melt crystallization. 


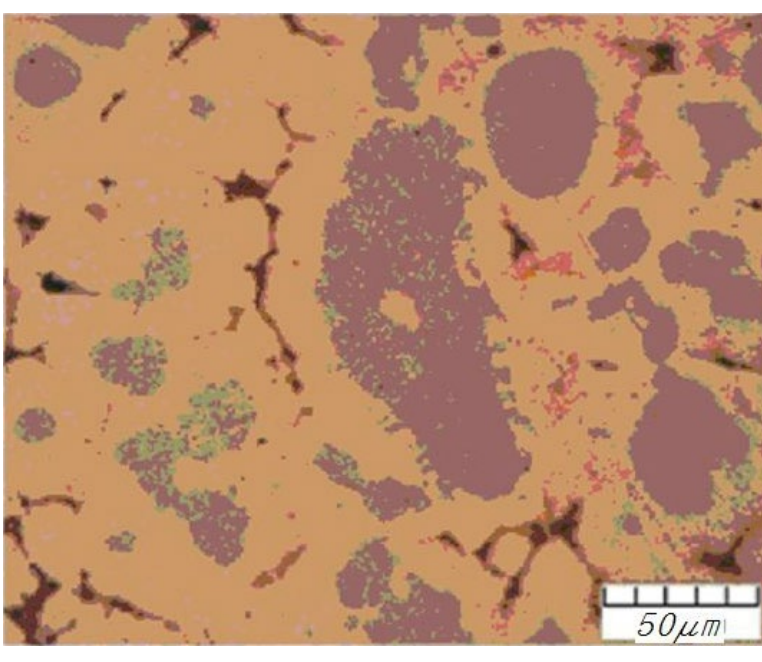

$a$

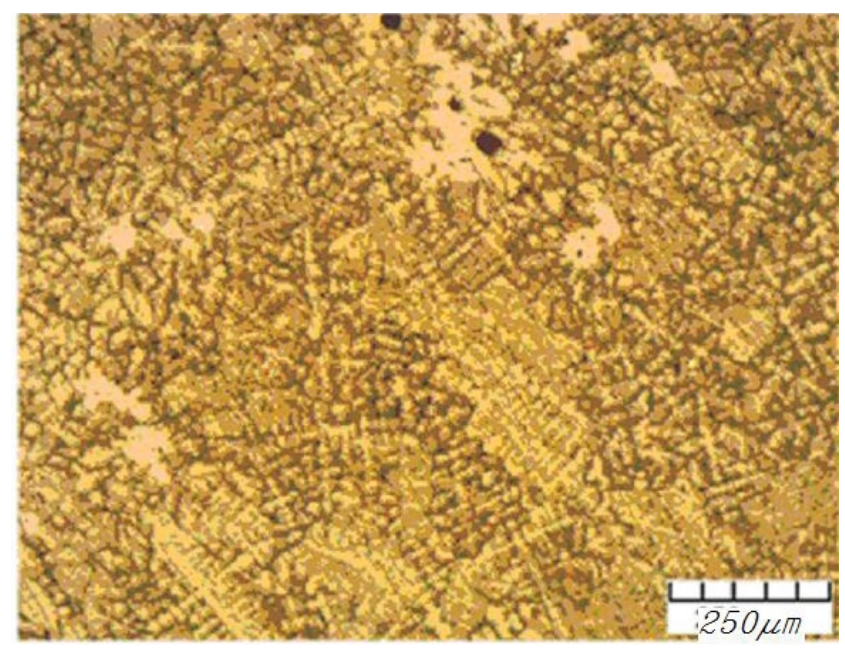

$b$

Fig. 3. Microstructure of solder $\mathrm{Cu}-36 \%$ mass $\mathrm{Zn}-10 \%$ mass $\mathrm{Ni}$ : $a$-heating temperature is $1200 \mathrm{~K}$ during $3 \mathrm{~s}$. Heating rate $35 \mathrm{~K} / \mathrm{s}$; $b$ - heating temperature is $1200 \mathrm{~K}$ during $6 \mathrm{~s}$. Heating rate $35 \mathrm{~K} / \mathrm{s}$

Such patterns formation in alloys obtained by contact interaction of refractory and low-melting components is possible. For this, the formation conditions need to be influenced by a high-frequency electromagnetic field in the formations of structurally inhomogeneous melts. After that, if a structurally inhomogeneous liquid-metal solution is cooled, this would reach the end to the formation of other structures than when a homogeneous solution is cooled. The formation of structurally inhomogeneous melts is possible if the components of the solder of $\mathrm{Cu}-\mathrm{Zn}-\mathrm{Ni}$ systems, $\mathrm{Cu}-\mathrm{Zn}-\mathrm{Ni}-\mathrm{Mn}$ systems are heated unevenly.

Heat generation occurs in iron (nickel) particles, which have an electrical resistance greater than low-melting component of the melt. According to morphological features, areas of inhomogeneous composition in grains cannot be attributed to any element of the solder microstructure: grains (dendrites), eutectic interlayers, intermetallic particles. Despite the differences in composition between the regions, there are no clearly defined interfaces (Figs. 2, 3). The areas of composition heterogeneity cross the boundaries between grains in separate areas of the solder microstructure. They are common for several grains (Fig. 3). It is generally accepted that the optimal structure of the solder in the brazed joint is the grain pattern of a complex-alloyed solid solution and ultradispersed particles of intermetallic compounds without pores, interlayers of eutectic between the grains [3], [10], [11]. Alloys of the $\mathrm{Cu}-\mathrm{Zn}, \mathrm{Cu}-\mathrm{Zn}-\mathrm{Ni}$ systems have a similar microstructure. As a consequence, solders have been developed for brazing hard alloys to steel holders and various grades of steels [2], [10]. An increase in the strength, technological (fluidity, chemical resistance) characteristics of solders is achieved mainly by complex alloying. This led to an increase in the melting point of the solder, and as a consequence, the soldering temperature rises. The introduction of dispersed particles (SiC, WC, etc.) into the composition of solders and the formation of composite structures presents significant technological difficulties. But this makes it possible to control the dimensions of the solder seam.

Solders, which are formed in the brazed joints of steel-steel, hard alloy-steel have a structure characteristic of composite materials. This occurs during the contact interaction of low-melting and highmelting components. Dispersed particles of copper alloy are present (with nickel, iron) in the copper alloy matrix. Some particles are morphologically associated with the surfaces to be joined (Fig. 4). Solder is alloyed by adding metal particles (nickel, iron) in the sintered mixture. This makes it possible to increase the concentration of the alloying element and increase the strength of the weld by the mechanism of dispersed hardening. The heterogeneity areas in the composition of the alloy (solder) in the brazed joint, which are obtained as a result of the interaction between the components of the mixture during brazing. These areas are morphologically associated with the surrounding alloy, and they contact adjacent surfaces (Fig. 4). 


\section{Mechanisms of Structural-Phase Transformations During Crystallization of a Solder Melt}

The heterogeneity areas of composition in the solders structure can also be considered as an element of their structure. They are similar to a particle of a dispersed (reinforcing) phase in dispersion-hardened composite materials. Depending on the metallochemical characteristics of the components in the composite solder, the conditions of soldering, the "dispersed phase" can represent an area of heterogeneity composition. In the systems $\mathrm{Cu}-\mathrm{P}-\mathrm{Fe},(\mathrm{Cu}-\mathrm{Zn})-\mathrm{Ni},(\mathrm{Cu}-\mathrm{Zn}-\mathrm{Ni}-\mathrm{Mn})-\mathrm{Ni}$, the dispersed phase in solders is mainly a heterogeneity area of the composition in the grain. In the systems (Cu-Zn)-Fe, (Cu-Zn-Ni-Mn)-Fe, the dispersed phase is predominantly a particle of an iron-zinc-copper alloy (Fig. $4 a$ ). Thus, the use of composite solders makes it possible to reduce the soldering temperature by $40 \ldots 50 \mathrm{~K}$, increase the concentration of alloying elements in the solder and change its structure. The indicated advantages of composite solders provide a decrease in the thermal effect on the joining materials, an increase in the strength of the seam and allow you to control the thickness of the soldered seam. This is important when brazing hard alloys of WC-TiC (TaC) systems.

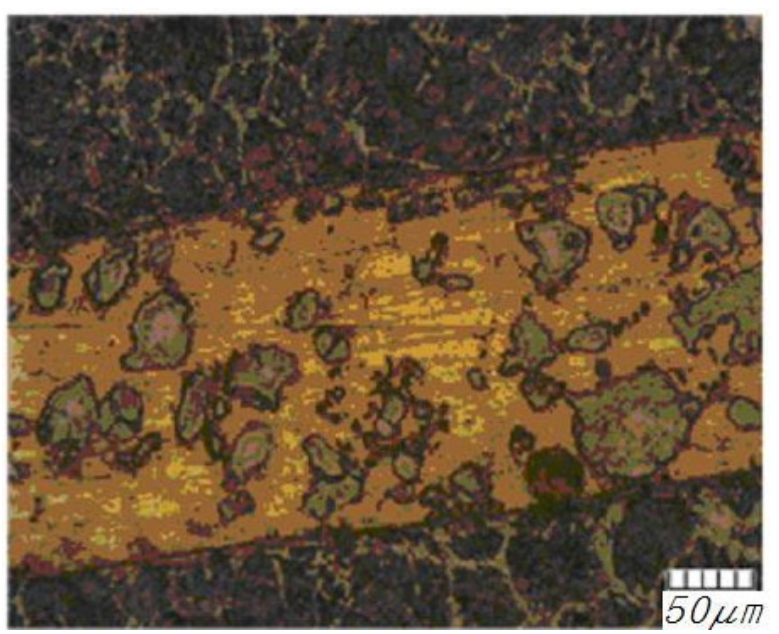

$a$

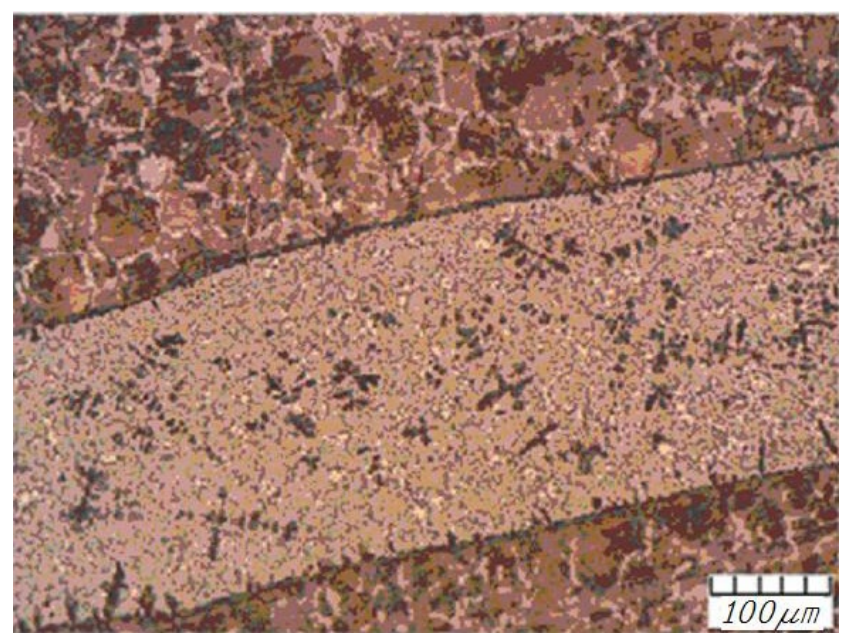

$b$

Fig. 4. Microstructure of solder $(a)$ and soldered seam $(b)$ : heating rate $40 \mathrm{~K} / \mathrm{s}$, soldering temperature $1200 \mathrm{~K}$, time for keeping $4 \mathrm{~s}$; $a$ - composite solder $\mathrm{Cu}-48 \%$ mass $\mathrm{Zn}-10 \%$ mass Fe; $b$ - composite solder $\mathrm{Cu}-48 \%$ mass $\mathrm{Zn}-10 \%$ mass $\mathrm{Ni}$

\section{Conclusions}

The research of the processes showed that during the contact interaction of low-melting and refractory components of the solders, when the tool was soldered, the solder is formed in the seam and proceeds through several stages. This does not lead to the formation of microstructures that are characteristic of alloys based on copper-iron-phosphorus, copper-zinc-nickel, copper-zinc-iron systems. High rates of dissolution of nickel particles in copper-zinc melts are due to the convection movement of the melt. Because it is affected by magnetic dynamic forces, resistive heat release in nickel (iron) particles, high values of nickel solubility in copper-zinc melts and copper solubility in nickel at the soldering temperature. This melt consists of a low-melting component. High initial dissolution rates of nickel particles in copper-zinc melts and solubility of copper and zinc in nickel led to the formation of quasiliquid particles of nickel alloy in the melt.

When the melt is cooled, the particles are formed with a composition different from the surrounding alloy and they are morphologically related to the grain structure of the solder. The resulting alloy (solder) has the structure of a composite material. Alloy particles are nickel-enriched. They contribute to the reinforcing element. Contact interaction of copper-zinc melts with iron particles does not lead to complete dissolution of iron particles. This is explained to the low values of the solubility of iron in copper-zinc melts despite the fact that resistive heat release occurs in the particles. Such iron particles (iron-based alloy) act as a dispersed phase in the structure of the composite material. 


\section{Anatoliy Kuzey, Vladimir Lebedev, Andrii Slipchuk, Pavel Tsykunov, Igor Yurchyshyn}

\section{References}

[1] Y. Liu, K. N. Tu, "Low melting point solders based on Sn, Bi, and In elements", Materials Today Advances, vol. 8, 100115, 2020.

[2] K. Tu, Y. Liu, M. Li, "Effect of Joule heating and current crowding on electromigration in mobile technology", Applied Physics Reviews, vol. 4, 011101, 2017.

[3] M. Thiyagu, L. Karunamoorthy, N. Arunkumar, "Thermal and tool wear characterization of graphene oxide coated through magnetorheological fluids on cemented carbide tool inserts", Archives of Civil and Mechanical Engineering, vol. 19, iss. 4, pp. 1043-1055, 2019.

[4] M. A. Khaskov, A. M. Shestakov, O. Yu. Sorokin, I. V. Zelenina, "Synthesis of carbon matrix with tunable carbide formation ability for reactive infiltration techniques", Ceramics International, vol. 46, iss. 13, pp. 21632-21637, 2020.

[5] K. Opeyemi, O. Yali Yao, X. Liu, D. Hildebrandt, "Synthesis, structure, and performance of carbide phases in Fischer-Tropsch synthesis: A critical review", Fuel, vol. 296, 120689, 2021.

[6] Y. Liu, L. Pu, Y. Yang, Q. He, Z. Zhou, C. Tan, X. Zhao, Q. Zhang, K. N. Tu, "A high-entropy alloy as very low melting point solder for advanced electronic packaging", Materials Today Advances, vol. 7, 100101, 2020.

[7] N. Cinca, B. D. Beake, A. J. Harris, E. Tarrés, "Micro-scale impact testing on cemented carbides", International Journal of Refractory Metals and Hard Materials, vol. 84, 105045, 2019.

[8] Y. Zhang, T. T. Zuo, Z. Tang, M. C. Gao, K. A. Dahmen, P. K. Liaw, Z. P. Lu, "Microstructures and properties of high-entropy alloys", Progress in Materials Science, vol. 61, pp. 1-93, 2014.

[9] M. Woydt, S. Huang, J. Vleugels, H. Mohrbacher, E. Cannizza, "Potentials of niobium carbide (NbC) as cutting tools and for wear protection", International Journal of Refractory Metals and Hard Materials, vol. 72, pp. 380-387, 2018.

[10] S. V. Lashko, N. F. Lashko, I. G. Nagapetyan, Proyektirovaniye tekhnologii payki metallicheskikh izdeliy [Design of technology for soldering metal products]. Moscow, Russia: Mashinostroyeniye Publ., 2014. [in Russian].

[11] Spravochnik po payke [Soldering guide], I. Ye. Petrunin, Ed. Moscow, Russia: Mashinostroyeniye Publ., 2003. [in Russian].

[12] V. S. Nemkov, V. B. Demidovich, Teoriya i raschet ustroystv induktsionnogo nagreva [Theory and calculation of induction heating devices]. Leningrad, Russia: Energoatomizdat Publ., 1988. [in Russian].

[13] A. N. Buzuyev, "Razrabotka i issledovaniye sistemy induktsionnogo nagreva dlya payki mnogosloynykh izdeliy" ["Development and research of an induction heating system for soldering multilayer products"], $\mathrm{PhD}$ dissertation, Samara State Technical University, Samara, Russia, 2006. [in Russian].

[14] V. S. Novosadov, S. V. D'yachenko, I. N. Pashkov, "Vliyaniye termicheskogo tsikla payki na strukturu i mekhanicheskiye svoystva staley" ["Influence of the thermal cycle of brazing on the structure and mechanical properties of steels"], in Proc. Int. Conf. "Payka-2008", Tol'yatti, Russia, September 10-12, 2008, pp. 15-24. [in Russian].

[15] V. G. Levich, Fiziko-khimicheskaya gidrodinamika [Physicochemical hydrodynamics]. Moscow, Russia: Izdatelstvo AN SSSR, 1952. [in Russian].

[16] G. A. Aksel'rud, A. D. Mozhanov, Rastvoreniye tverdykh veshchestv [Dissolving solids]. Moscow, Russia: Khimiya Publ., 1977. [in Russian].

[17] V. M. Zalkin, "Kontaktnoye plavleniye veshchestv, obrazuyushchikh evtekticheskiye sistemy s promezhutochnoy fazoy" ["Contact melting of substances forming eutectic systems with an intermediate phase"], Zhurnal fizicheskoy khimii [Journal of Physical Chemistry], vol. 53, no. 2, pp. 499-502, 1983. [in Russian].

[18] L. I. Ivanov, V. S. Zemskov, V. N. Kubasov, Plavleniye, kristallizatsiya i fazoobrazovaniye v nevesomosti [Melting, crystallization and phase formation in zero gravity]. Moscow, Russia: Nauka Publ., 1989. [in Russian]. 